\title{
The Anatomy of an AND
}

\author{
Janna Graham
}

\section{Gallery And Museum EduCATION AS AN "AND”}

Though gallery and museum education have increased in prominence and exposure in recent years especially in the UK, they are still often conceived of as an 'and' in many cultural institutions. This 'and' functions as either a bridge - a way in which to translate collections and exhibitions to publics and in some cases vice versa - or an add-on, an afterthought in the drive to make bigger and better attended spectacles. It is often narrated as the reason for galleries to exist and yet, it is the first program to go in budget cutting measures. This 'and' is nevertheless significant. It sits between objects and audiences, thematics and consequences, concepts and constituencies, the public-ness of cultural experi- ences and the material and affective conditions that shape them. Frequently the 'and' of education in galleries and museums must contend with and compen- sate for a gap between the promise of emancipatory encounters with culture and what Gayatri Spivak termed the 'mechanics of staging' the contradic- tory modes through which culture is produced; its deep entanglements with bourgeois hierarchies of taste making, colonial and state projects of pacification, and neoliberal managerial logics.

This 'and' of education is then a constituent aspect of contemporary culture- making. It is not only a concern for a particular department or profession, but experienced in all aspects of cultural organisation - from publics to artists, cleaners to curators, educators to accountants. Though these tensions have deep historical foundations they continue to circulate, often un-named and under-exposed in the everyday lives of cultural work.

\section{Thinking with Conditions: Terms that Lie Beneath}

Where questions about curating and education have recently come into greater proximity, ${ }_{1}^{1}$ there is often a focus on the details of who is called what, who is responsible for what and who is qualified for what. These often obscure and distract from the larger conversation that could be had, about the contradic- tions between the emancipatory educational rhetoric of cultural institutions and their organising practices. This is dangerous in two ways: in distracting educators, curators and others from the way in which their work is used to support processes that run counter to emancipation, in, for example, regressive urban and social policy, where both arts commissioning and education have come to play an increasingly important role; and in leaving under-practiced and under-theorised the affinities that might be aligned beyond job descriptions and based on common commitments to emancipatory social change.

What would it be to name and respond to the conflicts and contradic- tions that surround this AND, conflicts that are washed over in the details of everyday cultural work and the bureaucratic formulation of the relationship between educators and curators? What cultural field would emerge if mapped out around common commitments to emancipatory pedagogy, social use and post-capitalist 
existence? Who would be aligned and who would not? What tools do histories of emancipatory education lend to us to analyse and act upon these conditions?

This paper makes a modest attempt at answering these questions by way of tools derived from radical education practices that I have elsewhere described under the common heading 'thinking with conditions'. Developed particu- larly in relation to my own experiences of the dis-continuities between what is shown in the (often utopian), representational aspects of culture-making and what is experienced in its modes of production, thinking with conditions is a call for attention to the relationship between these two terrains. ${ }^{2}$ Or as the British conceptual art collective Art and Language once suggested, to under- stand "what historical conditions we are really in, rather than those we want, need, believe or feel intimidated into supporting...". ${ }^{3}$ The first of the tools I'll introduce is offered by the praxes of Institutional Pedagogy. Developed by Jean and Fernand Oury in $1958^{4}$ for understanding the learning that takes place in institutions that goes beyond its intended learning activities - what another emancipatory educator, Ivan Illich, described as the Hidden Curriculum $^{5}$ - Institutional Pedagogy gave school-based and psychiatric practitioners a framework to analyse conditions beyond the explicit architectures or bureau-cratic formations of the institutions and their outputs. They invited practitioners to understand institutions as a series of performative pedagogies that take place within and beyond institutional walls. The second tool introduced here draws from the work of Latin American popular educators whose grounding in the Pedagogy of the Oppressed ${ }^{6}$ has developed methodologies for 'naming the conflict', and exposing and acting upon the contradictions that colonial and capitalist life experience produce. A third tool is offered in the figure of the para-site drawn from the work of philosopher Michel Serres and my own work with contemporary social activists, ${ }^{7}$ to indicate a kind of institutional inhabition that sits within formations with which it does not agree, re-organising practices of institutionality through being and behaving otherwise.

These three modes of thinking with conditions are explored against the backdrop of tensions and conflicts experienced in the first five years of devel- opment of the Centre for Possible Studies, an off-site education and curatorial project of Serpentine Gallery, ${ }^{8}$ in which artists, educators and activists, have generated 'studies of the possible' in relation to urban inequalities in London's Edgware Road neighbourhood. These inequalities are shaped by a number of processes derived from the position of the Road in central London, in the borough of Westminster in an area that is home to some of London's wealthiest families living on land bequeathed to the Church and local aristocrats in the 16th century but also an area known to be a centre for migrants from many parts of the world. The shisha cafés and migrant-owned businesses on the southern part of the Edgware Road - adjacent to the famed 'Speaker's Corner', inciden- tally a former site of public torture -, provide a gateway for new migrants in terms of both employment and cultural life, though they are unlikely to be able to afford to live in the area for a long period of time. Nonetheless, these are sites of informal education, political organisation, cultural production and entertain- ment ${ }^{9}$. New interests in 'lifting' the area amongst the wealthier residents and their Tory representatives in the Westminster Council have explicitly sought for migrant businesses to be brought into line with the vision for the area, and the languages of both plastic surgery and (behind closed doors) 'hygiene' are

regularly deployed to describe both the beggars in the area and the appearance and character of local businesses. ${ }^{10}$ Further along the Edgware Road, an area called 'Church Street' is currently experiencing a classic gentrification process. The local area is home to white working class people, new migrants, and partic- ularly refugees, who live in tall blocks of social housing. Many of these are due to be torn down in the name of 'regeneration'. driven by the local Council and private 
developers working in partnership. Combined with planned changes to the housing benefit system, this has had the effect of displacing poor residents to other parts of the city and country. ${ }^{11}$ The Serpentine Gallery and other main- stream arts organizations are seen by the forces of development on both ends of the Road, as an asset to the development process, both in their ability to signpost 'important' artists for public commissions, but also for their author- itative interest in the aesthetic dimension of urban planning. And though the Centre for Possible Studies received no direct funding from developers and Council members, gifts in kind such as the empty buildings used as our base linked us to this process, rendering it necessary to both understand the situation and to take sides. The name of the Centre for Possible Studies itself was created as a response to these processes; many local residents who felt the force of impending displacement described the local 'studies' undertaken by developers and government as failing to reflect their perspectives on what could be possible for the area.

Drawing from my own experiences as the named curator of the Edgware Road Project and recorded speech acts surrounding the project by gallery workers, local officials, young people, self-organised sex workers and partic- ipating anti-racism theatre workers, this paper will highlight the affini- ties, tensions and disconnections that emerge through processes of putting 'thinking with conditions' into play in the cultural field.

\section{Towards a Pedagogy of Institutions}

What do culture-making practices teach us against the grain of their intention? This is a question with which I have begun seminars with current and prospective cultural workers over a number of years, in which we diagram the anatomy of political art and pedagogical projects from their conceptual underpinnings through the practice of their organisation. They often begin with a good intention, a noble aim, like 'sharing information about environ- mental destruction' or 'working against border control', or 'creating a platform

to challenge neo-liberalism'. As we move through our descriptions of the production cycle, a pattern begins to emerge: a context is created by a director or Board of Trustees, an idea generated in response by a curator or educator, often in collaboration with an artist, and from there it is delivered to a public, by way of programmes, marketing vehicles, front of house staff, fabricators and installers, security guards, caterers, cleaners and publics. Sometimes, constituencies or groups deemed relevant to the thematic at hand are sought out for engagement, usually in the project's later stages. The time associated with this engagement is often cut short, subject to available resources and the time slot allocated to the project, not exceeding the cultural moment in which the thematic has been deemed to have been of interest. As one moves down the chain, the conditions of work become more precarious, and the process of production less transparent to those involved.

The focus of attention and discussion in this anatomy - even through critical approaches like institutional critique - is on the moment of presenta- tion or delivery, leaving the myriad of other practices that go into the making of culture under-examined and under discussed.

Attempting to understand the dynamic between pre-representational, representational and postrepresentational aspects of institutional life and its more recognizable presentational aspects, is at the heart of what Jean and Fernand Oury described in 1958 in France as Institutional Pedagogy. Working across the 'big architectures' of institutional provision such as the psychiatric clinic and 
the school, practitioners of institutional pedagogy engaged teachers, students, parents, psychiatrists, cleaners, service users, and artists in a process of identification of the way in which institutions are performed, learned and taught, both within their walls and through their relationships in families, communities and their place in social history. They understood institutions as both the bricks and mortar, the bureaucracies and architectures and rules that visibly enforce its structure, but also through the often conflicting narratives and desires that shape them, understanding them rather as 'life places' that cut across and beyond what is commonly understood as 'the institution'. Their commitment was not only to the analysis of the explicit and implicit learning practices that institutions produce, but to intervention, breaking from these practices and substituting alternative forms which would radically re-shape institutions around principles of social justice. Derived from an encounter between primary schools developed in the Ecole Moderne (or Freinet) ${ }^{12}$ movement in France in the 1940s and 50s - in which students were encour- aged to remark upon and alter the organisation of the school through collabo- rative use of a printing press and school councils, and the adaptation of these techniques to residential psychiatric institutions, Institutional Pedagogy was

equally situated in pedagogical and psychoanalytic terrains. Working across the various constituencies of education, it thus produced what Felix Guattari described as a 'transversal' analysis of the unspoken structuring devices, ${ }^{13}$ those 'that makes it possible to use a soap without quarrelling' as well as 'the whole of the rules allowing to define what "can or cannot be done". ${ }^{14}$

Institutional Pedagogy suggests that beyond the monolithic understanding of institution, configurations of us and them and inside and outside, there are instituting practices, 'micro-groups of interests and micropolitics of affinity and aversion based in desires and eruptive relationships. Understood micro- politically, institutions then, do not only comprise those people on the payroll, those in this or that role, but a much wider constituency of interests, subjectiv- ities and desires. They are social, creative and productive sites.

This bears importance in thinking about cultural institutions in three ways: one, in thinking against the notion that the social somehow sits outside of the walls of cultural production and what is presented as art, through marketing surveys or otherwise; two, in countering what are often homogeneous readings of the institutions of culture, which - whether critical or affirmative - tend to take the brand at its word and leave little space for unpacking the conflicting interests that shape such establishments and the learning they ask others to do; and finally in attending to the those aspects of learning that are the least visible, which in cultural institutions often have tremendous power in securing hegemonic structures through cultures of coercion, submission and silence.

Methodologically, institutional analysis consists of the use of 'micro-mono- graphic studies' undertaken by those working in the expanded field of an insti- tutional entity, by groups of those affected to form the basis for their interven- tion. Central to this is the notion of working through the texts, or speech acts of those engaged in instituting. As Jacques Pain, in his review of institutional analysis and its relationship to violence suggests, 'Institutions talk (speak) insofar as there exist places of listening'. ${ }^{15}$ The practice of listening to how insti- tutions talk, enables their conceptual apparatus to be exposed, transposed and adapted to intervene in the 'life places' that they produce.

If we understand cultural institutions through this expanded definition - as sites of productive institutional pedagogy - how might such an analysis be carried out? 
The Anatomy of an AND 193 SPEAKING THE INSTITUTION IN ITS EXPANDED

\section{Form: 'They Will bring a Strong Curatorial Vision to the NeighbourhoOd'}

In 2008, I was invited by the Serpentine Gallery to develop an arts project in the Edgware Road neighbourhood. The project was instigated out of a long term relationship between the Gallery and people in the neighbourhood - developed both through standard kinds of gallery education like exhibition-related school and community visits, and through special projects, the most recent of which had been a two-year residency involving artists working in a local school. As a result of this, people in the area indicated they would like the relationship to continue. ${ }^{16}$ It was hoped that it would be able to experiment between models of curatorial public commissioning and gallery education. It also grew out of the Gallery's interest in the neighbourhood as representative of the 'Middle East' and therefore a conduit to international artists and institutions in that part of the world. Later, the project was re-configured to act as an agent and ally in struggles against the gentrification processes in the neighbourhood described in the introduction of this text. These contradictory interests in the project revealed themselves in its early stages. As such, for myself and the artists and activists involved in conceptualizing the project, it was necessary to create informal "places [or practices] of listening' to register the many kinds of institu- tional talk that were emerging, both from the gallery and in the eyes and minds of others in the neighbourhood. Through these listening approaches a number of rhetorics emerged about the institution in its expanded form:

- A democratising rhetoric: that we would 'change society,' 'be of use to those most marginalized,' 'focus not on outreach for the gallery, but providing tools for the neighbourhood', be a 'temporary autonomous zone', 'change percep- tions of the area', 'change art practice,' 'remove divisions between educators and curators', enable 'horizontal' and 'bottom up' processes of decision-making against the top down cultures of the gallery and local government;

- A bureaucratic rhetoric, suggesting that the project might 'tick boxes', provide 'integration' for local migrant communities, 'regenerate' the area, and provide a 'strong curatorial vision' for the neighbourhood;

- A vanguard rhetoric, which particularly focused on the commissioned artists who would be 'up and coming' and might, through their prominence in the art world ' bring greater focus to participatory or 'community' work; and

- A rhetoric surrounding the brand, asking 'how will people know it is a Serpentine project?' and how will they know 'we' worked on it?

The contradictions found in these various rhetorics signalled the strange inter- sectional terrain such projects occupy in this moment of high neo-liberalism - both democratizing and paternalistic, socially oriented and market produced, full of idealism and concession. They are underwritten by a dualistic archae- ology of past collective struggles for social justice and contemporary modes of hegemonic appropriation and privatization. For instance, some of this rhetoric echoes arguments 
made by gallery educators throughout the 1990s: that we should, as Irish Museum of Modern Art director Declan McGonagle used to say, form "the temple and the forum together"; ${ }^{17}$ that artists themselves had turned to the participatory, the pedagogical or the 'relational' and therefore education was an important site for commissioning these new forms and should also bear the title of curating; that additional state, foundation or corporate funding could be generated by education projects; and that these projects would generate important experiences for people who may consequently become future gallery goers and advocates.

They also resonate with elements of urban policy shifts implemented in the transition from the 1970 s to the 1980 s, during which London politicians described urban emancipatory arts movements as keeping local people's perspectives focused on the 'positive aspects' of development. ${ }^{18}$ Employing this logic to benefit from the paradoxical status of the arts as that which exists for the 'public good', while at the same time affirming class hierarchy and social elitism, governments and developers now frequently enlist artists and arts organizations at all stages of the development process, in what David Harvey describes as a movement from ethics to aesthetics in urban policy of the post- modern era. ${ }^{19}$ That a local planner's expectation that the involvement of an art gallery, as cited above, would bring a 'strong curatorial vision to the neigh- bourhood' can be understood in terms of representational aesthetic outcomes, but also reflecting the aesthetics of the organising practices surrounding insti- tutional art commissioning, in which 'curatorial vision' is synonymous with dissociation from affected publics. Placed above the 'riffraff' of concerns found in democratic process - i. e. the radical reduction of social housing, the sustain- ability of street market prices for working class people - here the AND of arts pedagogy is a euphemism for the coercive, soft diplomacy approach to develop- ment, that produces a mirage of engagement around futures that have already been inscribed and which will be violently secured through the collusion between councils, developers and police.

In this cacophony, murmurs of recurring social justice movements - calling for the arts to be of social use, aligning with the interests of the poor, and embedding the accountabilities of art and education to the struggles that they serve - are also audible. However they lay in a tension between what Hansel Hndube Eyoh describes in his work on radical community theatre groups of the 1970s and 80 s as the 'domestication' of radical cultural movements, who, seeking acceptance of their work, often forget the broader aims of their project: the radical liberation of society from oppression. ${ }^{20}$ Losing sight of this latter goal keeps practitioners struggling with problems created by bureaucratic organ- ising practices, and not focusing on the 'impossible' demands that fall outside of existing logics and call for more fundamental change. This management of demands and desires is a central feature of neoliberal governance strategies.

\section{Naming Conflicts, but Not in Name Only}

One of the ways in which professionals become alienated from social move- ments in the way Ndumbe Eyoh describes, is in failing to practice within the spaces where the impossible demands for social justice are made. As an extension of this, those who possess the deepest knowledge and intelligence about social injustice are re-cast as 'audiences', 'participants', 'users', 'vulner- able communities' and through this act of naming become 'other' to even the most emancipatory aims of institutions, needing therefore to be 'attracted', 'captured', 'targeted', 'engaged' etc.

If we are to truly understand the institution in its expanded and peda- gogical form, by the utterances and micro-circumstances through which it is instituted, it is crucial to listen to those who make institutions from the social spaces deemed to be its outside. 
Beyond listening to the rhetorics of those with founding stakes in the Edgware Road Project, in 2009 we created the Centre for Possible Studies as an archive and community resource located in abandoned buildings on and off the Edgware Road with a strong commitment to social justice. For the community groups and artists who work as part of this itinerant entity, the study and praxis of popular education has become a central feature. This study has guided us in thinking through how we might make considered and critical interventions into the contradictory forces at play in the shaping of our work. Like Institutional Pedagogy, popular education practices invite groups to analyse and re-frame the terms through which they name the world. In Pedagogy of the Oppressed, Brazilian educator Pablo Freire outlines a process through which people use collective analyses of their experience of power as the basis for the creation

of the terms of understanding and intervention. This practice, involving both representational and non-representational methods, which Freire describes as 'codification' and 'de-codification', seeks to name and act upon contradic- tory conditions. Freire's dialectical notion of action and dialogue in which action with no dialogue is simply 'activism', that is, unthoughtful response, and dialogue without action is seen to be akin to an 'alienating blah blah blah' ${ }^{21}$ - underpins this commitment. Though Freire's own writings are more focused on the process of consciousness-raising and much less so on how groups move from these activities to taking revolutionary action, Freire-inspired radical education workbooks used by the Sandinistas, the anti-NAFTA movements of the late 1980s, and others, suggest that naming (and heightening) conflicts around oppression forms a crucial aspect of popular education. Naming here goes beyond the creation of new terminology and moves into the cultivation of action. It is here where emancipatory popular educators can be understood as different from the many 'participation' and 'engagement' practitioners who use popular education methods and tools to secure state and corporate power and the global distribution of capital. ${ }^{22}$ Where for this latter group, popular education provides a set of tools, for emancipatory educators, 'naming the conflict' is a commitment to the radical contestation of oppressive structures in alignment with those who experience them the most profoundly.

Over the course of the last five years of the Edgware Road Project, we have engaged in the collective practice of 'naming the conflict' with migrant and non-migrant people engaged in theatre workshops, which came to be known as Implicated Theatre. As a core and on-going group at the Centre, Implicated has adapted strategies of popular literacy and theatre to create projects that analyse the different and overlapping issues facing the group's precarious migrant people and cultural workers. The group's name, "Implicated", emerged through the use of Augusto Boal's Theatre of the Oppressed to create images (Boal's term for body tableaux) in which it became clear that the formulation of oppressed/oppressor did not adequately reflect the ways in which the group experienced their own power, nor that of oppressive forces. Where in Boal's work there is often an expectation that these entities be distinct, in workshops based on contemporary conditions, the oppressor was often multiple with its many faces, and its life inside of each of member of the group. Translated into the many languages of participants, 'Implicated' was the term that the group used to both describe this condition but also to indicate the group's desires to be "implicated" in one another's lives through acts of solidarity.

The group has named a number of conflicts related to migrant experience, developing theatre pieces to support London-based campaigns, including the anti-raids network, a migrant-led coalition that develops tools and direct action interventions against state sanctioned immigration raids; Justice for Domestic Workers, a group working for better conditions for migrant domestic labourers; and the 
Unite Hotel Workers union, a fringe division of the Unite union that works from migrant worker experiences to develop new tools for organising in the hotel sector.

Equally significant, the group used naming practices to question its own internal power relations and distribution of resources instigated through its relationship to its "host" organization, the Serpentine Gallery. There are various positions from which these naming practices take place, with some members unfamiliar with the Serpentine and the context of contemporary art in London, and others aware and very critical of its role. This dynamic has manifested in a number of performances involving the various constituencies in the project: cultural workers, gallery staff, middle class audiences, migrant rights organiza- tions in thinking through the conflicting terrain of this relationship.

One such performance, titled The Embassy Ball, looks at the dynamic between the bourgeois tastemaking apparatus of the Gallery and those who often constitute the cleaners and flexible catering service workers of such places. Parodying the dress, atmosphere and speech-making procedures of these events, guests to the theatre piece (re-positioned as guests of this private party) bear witness to the staging of mini rebellions in the proceedings based on worker experiences, with discussions about the very conflicts that enable such projects to occur.

The making of this theatre piece was based on weeks of workshops on our own implications in these enabling contradictions. Questioning the distri- bution of power and resources, we began to unravel the micro effects of the gallery's organising principles - that projects be instigated by curators and artists for participants in the name of 'training', that resources be distributed accordingly, that those artists be identified with the project more prominently than 'participants' who are often not acknowledged at all, that 'participants' supply stories while aesthetic responsibility is held by artists and representa- tives - which in spite of conscious decisions to collaborate equally, often crept into the working practices of the group.

As a result of this process of naming our own conflicts, we began to re-shape these practices. Collective budgeting was undertaken to determine fair compensation and organisation of tasks, 'participants' studied to become facilitators and decision-making was collectivised. This was and is not simple, bringing about a number of core debates: whether gallery funds should be

used to engage in support and solidarity of members i.e. emergency food and housing, whether everyone should be aligned with the political 'causes' we worked with (i.e. some in the group had more positive relationships to the police than others). These questions enabled us to confront the framing of the project as 'education'. Questions of power in broader oppressive contexts came to reflect on the instituting practices of the group and the desires and necessi- ties that hold them in place. For example, most funders of pedagogical projects require that a 'problem' be framed for a constituency in advance, and most commissioning projects require that funds be distributed to what is seen to be 'artistic' work and not to the re-distribution of wealth, aesthetic responsibility and organising power as was the group's desire. In order to contravene such requirements, it was essential to build sufficient trust to be very frank in collec- tive conversations.

Identifying and acting upon conflicting agendas had some (though minor) broader impacts on the gallery, the most pertinent one being its politiciza- tion of staff members (namely within the programming department) who worked to revitalise the gallery's internal trade union and began to question its hegemonic organising practices more explicitly. This certainly did not instigate revolutionary changes to these practices, but began the process of opening up spaces for collective discussion and action, with much more work to be done in directly engaging the gallery's core donors in dialogue about conditions for migrant workers. 
The institution revealed through this process is complex. Its shape can be seen not only in its individual impacts: i. e. "analysing oppression and our rela- tionships as a group"; "learn[ing] a lot about rights and other people's experi- ences", or "finding hope in the very difficult situation of things you cannot do"; but also in the collective experience of being framed by a gallery (the Serpen- tine) deemed by some to present a "brutal and violent model of cultural produc- tion that is utterly de-humanising". ${ }^{23}$ It also exposes the fracture in interests between group members with existing experience of the context of the art world, for whom questions of the gallery's framing were much more pertinent that those who participated in the project with no relationship to the art world at all, for whom the mutual support offered was far more pertinent. The disjunc- ture in the kinds of critiques, driving factors and basic conditions for those involved in the group is a constituent element of the project and reflects the contradictory terms under which such projects are instituted. It is through a continuous process of reflecting on how dynamics of oppression produce such discontinuities - rather than trying to rid ourselves of them - that we have created the ground for affinities and acts of solidarity between cultural workers who have experience within the art world and those who are deemed to be its outsiders. These solidarities begin to map (or as one group member suggested 'rehearse') the contours of what another model of cultural instituting might look like.

\section{InSTITUTION AS TRAJEctory: PARA-Sitic OCCUPATIONS}

In the expanded experience of the cultural institution that I have described, one understood through the contradictions and conflicts it produces for those it deems to be outside, institutional discontinuities operate on a trajectory between total disinterest and total disagreement.

This trajectory has been registered by another resident group of the Centre for Possible Studies, the x:talk project, a sex worker-led workers co-operative which provides free English classes to migrant sex workers in the area. x:talk use popular literacy methods to teach English language as an organising tool for sex workers who are increasingly policed as part of the gentrification of urban neighbourhood neighbourhoods. Created by and for migrant sex workers, the project supports critical interventions around issues of migration, race, gender, sexuality and labour, and participates in feminist and anti-racist campaigns.

x:talk spent more than five years at the Centre, having primarily used hospitals as their base in the past, one of them located just of the Edgware Road. Historically related to the involvement of sex worker groups in community organising around HIV and harm reduction campaigns in the 1980s, the group joined the centre because it wanted to leave behind the stigma associated with "the medical obsession with the prostitute's body, which has to be prodded and poked to understand its social deviance" 24 . Moving to an arts context, says the collective spokesperson Ava Caradonna, "shifted the emphasis off the body of the sex worker, and the idea that sex work is exclusively held within a bodily form". 25

In spite of this x:talk was sceptical of the affiliation with the Serpentine gallery and the art world's over-emphasis on representation. As Ava stated, "We will not simply perform for the artists, researchers and reporters that want to do their project on sex work [...] Our work is in solidarity with the movement."

Comparing the structure of cultural institutions to those of sex worker organizations run from above, Ava suggests,

We are familiar with this one-way dynamic also within sex worker organising, which often favours the solo lone spokesperson celebrity over the many who might be working on the ground. Our 
response is to create organic modes of representation that lend themselves to kinds of organising, that is, to create a kind of laboratory for organising.

Rather than engaging directly with the so-called institution of culture as the subject of change, $\mathrm{x}$ :talk rather positioned it as a host for a para-sitic operation, providing the context for organizational experimentation,

it meant that we were able to secure our first big grants, as we could use the free rent in central London offered by the Centre for Possible Studies as match funding [...] Through this we gained enough stability to go on to the next step and open an autonomous space in the East end [...] so it was a kind of a mid point and a laboratory, for us.

Laying claim to the figure of the para-site as a non-heroic but critical and resistant agent has been an important re-positioning of the avant-garde political subject for many involved with emancipatory education projects in galleries, who seek to find spaces for their own articulation outside of the spectacular- ising contexts of both art and heroic politics. Drawn from their own readings of feminist consciousness raising and anti-colonial projects, the para-site is characterised by $\mathrm{x}$ :talk as an occupation of an organisation with whom they fundamentally disagree. ${ }^{26}$ Working in opposition to their host organisation, they refuse its logics, and therefore do not try to reform but rather antagonise, drawing resources to engage in social change of a more radical nature. As Caradonna describes, "this para-sitic strategy is used by many activists who are challenging essentialised identity categories when they engage with bigger institutions".

This assessment of the role of cultural institutions does not exclude the notion of institutional change but intervenes in its discourses by refusing the spectacular terms of involvement set out by cultural organizations, opting rather for their re-distributive capacity. The para-site is not presented as an ideal type in the figure of change but offers a sense of what is possible in cultural environments that are highly compromised. It also offers insight into the para aspect of para-sitic practices as described by Eyoh, of emancipatory cultural practices maintaining a commitment to social justice rather than to their bureaucratic role within cultural or other institutions.

This is not an argument for a wholesale evacuation of lobbies for policy changes, fair pay, a fundamental re-organisation of cultural institutions around emancipatory accountabilities, multivocal community boards, and against corporate involvement in the arts, but to suggest para-sitic activity as a site of learning for how re-figured cultural institutions might look, and for affirming what we are fighting for.

\section{From the ANATOMY OF AN AND to AN AND AND AND}

In his writing on Godard's television series Sixfois deux many years ago, Gilles Deleuze made the distinction between two kinds of AND. One was the AND that affirms What is on either side of the conjunction, that which affirms natu- ralized concepts of the inevitable and the status quo. The other is the AND of a "creative stammering", the "and (... and ... and)", that is a force of becoming multiple, "of living and thinking", to see the boundaries and surpass them. ${ }^{27}$

In looking closely at this AND function of pedagogies, expanding our readings - our anatomical understanding - of what the institutions of culture produce, is critical. While much important work has been written about the ways in which cultural establishments collude with power, it is equally important to look to those engaging with them to produce counter-power activities, those outsider agents, those micropolitical forces and conditions of experience that activate gallery pedagogy as a terrain of conflict and struggle. What institutional analysis, naming the conflict and the figure of the 
para-site provide are precisely other avenues for doing so, for thinking with current conditions in a way that is insistent on another way of instituting the institu- tions of culture.

1 I P. O’Neill \& M. Wilson, Curating and the Educational Turn.

2 | J. Graham, Between a Pedagogical Turn and a Hard Place.

3 I C. Harrison, Conceptual Art and Painting, p. 27.

4 I F. Oury \& A. Vasquez, Vers une pédagogie institutionnelle.

5 I I. Illich, Deschooling Society, p. 56.

6 I P. Freire, Pedagogy of the Oppressed.

7 I See M. Serres, The Parasite, and the manifesto by media activist collective CAMP, https:// pad.ma/texts/padma:10_Theses_on_the_Archive/10, and interview excerpts with sex worker rights group x:talk quoted in this essay.

$\mathbf{8} \mid \mathrm{J}$. Graham, et al., On the Edgware Road.

9 | For more information about the history of migrant businesses and their interaction with local policy in the area, see CAMP, A. Khalaf, \& J. Graham, Pleasure: A Block Study.

10 I See official plans and language for the area at: www.edgwareroadpartnership. co.uk/

11 I https://www.westminster.gov.uk/church-street-neighbourhood-regeneration.

12 | A. Vasquez \& F. Oury, The Educational Techniques of Freinet.

13 | F. Guattari, The Transference, p. 63.

14 I Fernand Oury quoted in J. Pain, Institutional Pedagogy.

15 | Ibid.

16 I S. Tallant, 'School of Thought' in Dis-assembly, p. 9-14.

17 I D. McGonagle, The Temple and the Forum Together, p. 21-24.

18 I See, for instance: GLC: State of the Arts or the Art of the State; LCC: An Arts and Cultural Industries Strategy for Liverpool; URBED, Developing the Cultural Industries Quarter in Sheffield.

19 I D. Harvey, The Condition of Postmodernity, p. 6.

20 | N. H. Eyoh, Beyond the Theatre.

21 | P. Freire, Pedagogy of the Oppressed, ch. 3.

22 I An astute analysis of the ways in which popular education in Latin America has been co-opted by progressive governments to create tools for engagement without questioning fundamental 
structures of state power or the global distribution of capital can be found in R. Zibechi, Territories in Resistance, ch. 4.

23 I Quotations transcribed from a group discussion held in September 2014 by Impli- cated Theatre members (unpublished).

24 I Transcript from an interview with Ava Caradonna. January 2015 (unpublished).

25 I Transcript from an interview with Ava Caradonna. January 2015 (unpublished).

26 I See for example the issue Care Work and the Commons (The Commoner No. 15 at www.commoner.org.uk/) used by x:talk members to frame aspects of their analysis.

27 | G. Deleuze, Trois questions sur 'Six fois deux', p. 271.

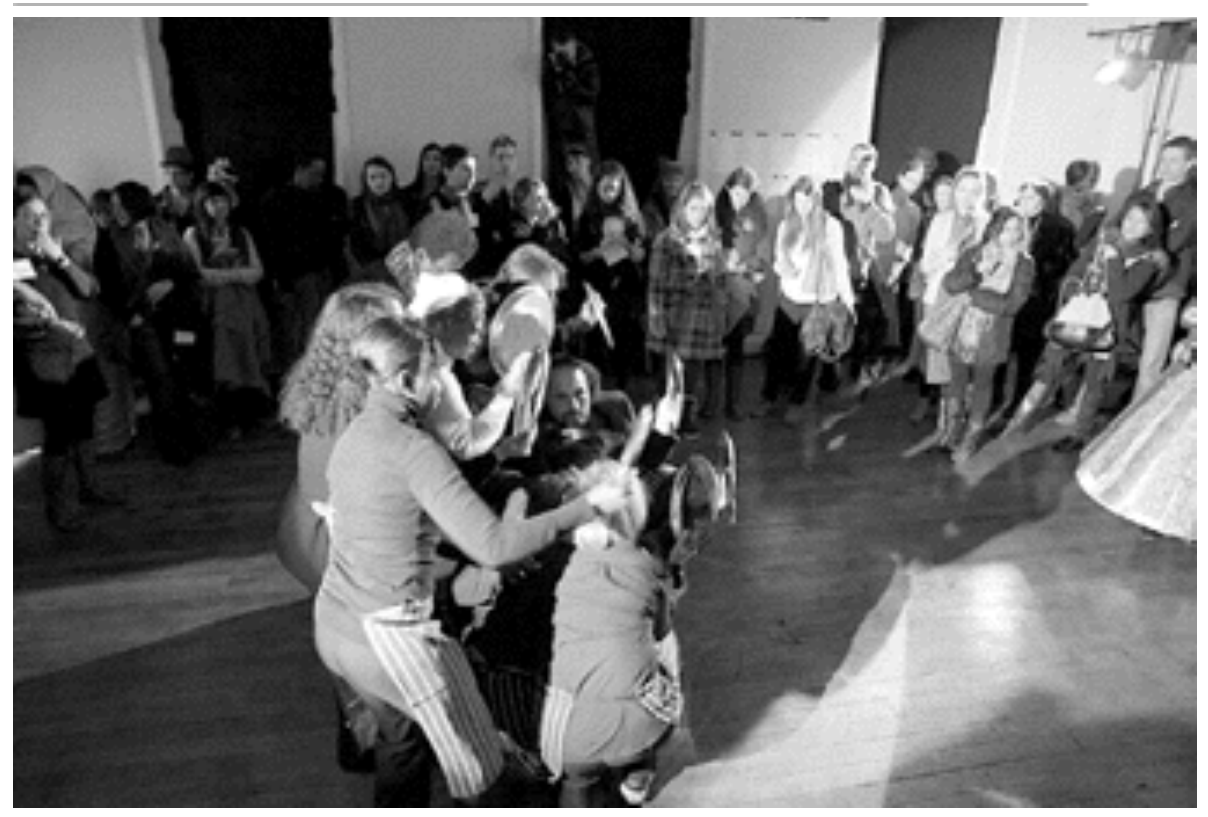

Figure 1-4: The Embassy Ball. 


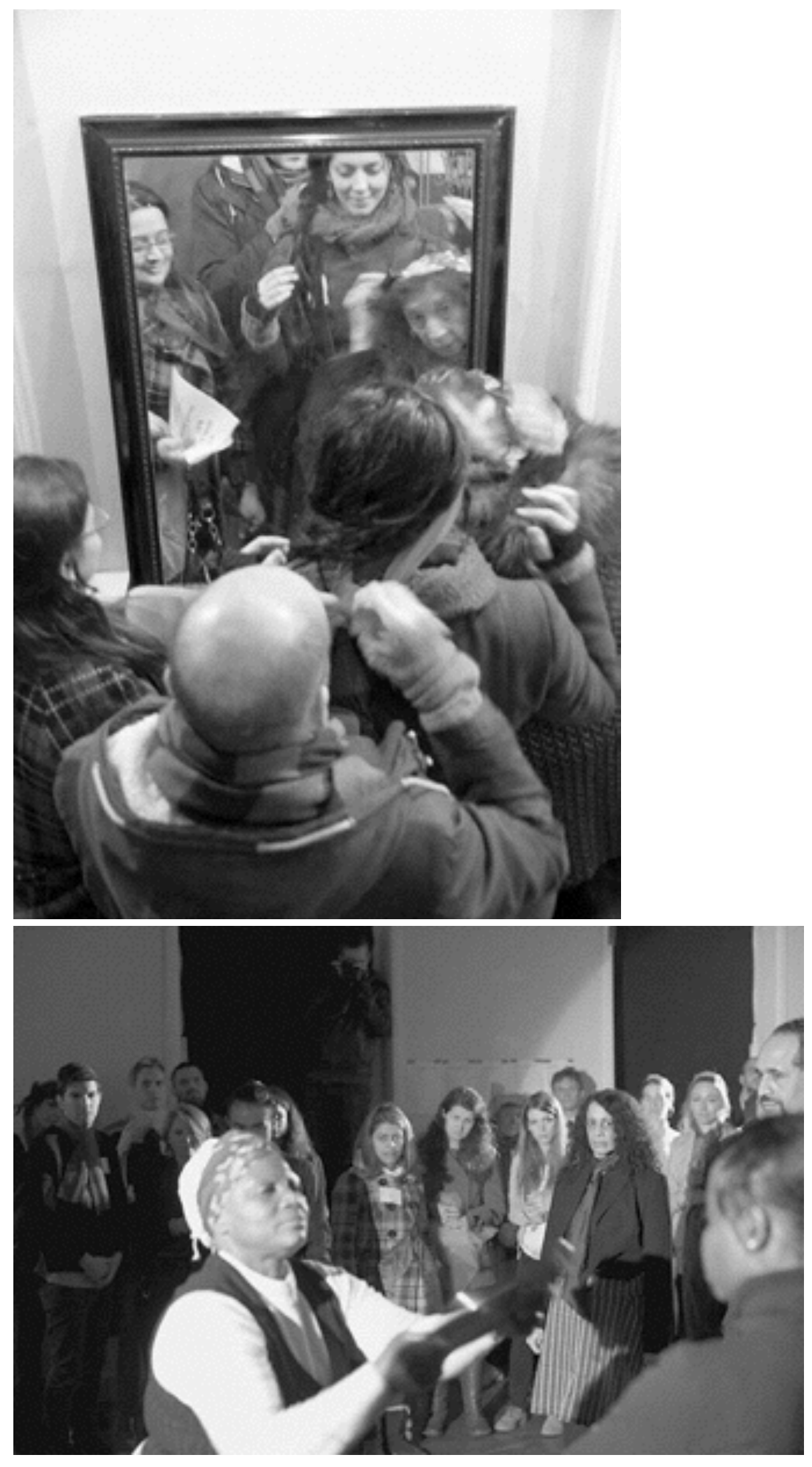




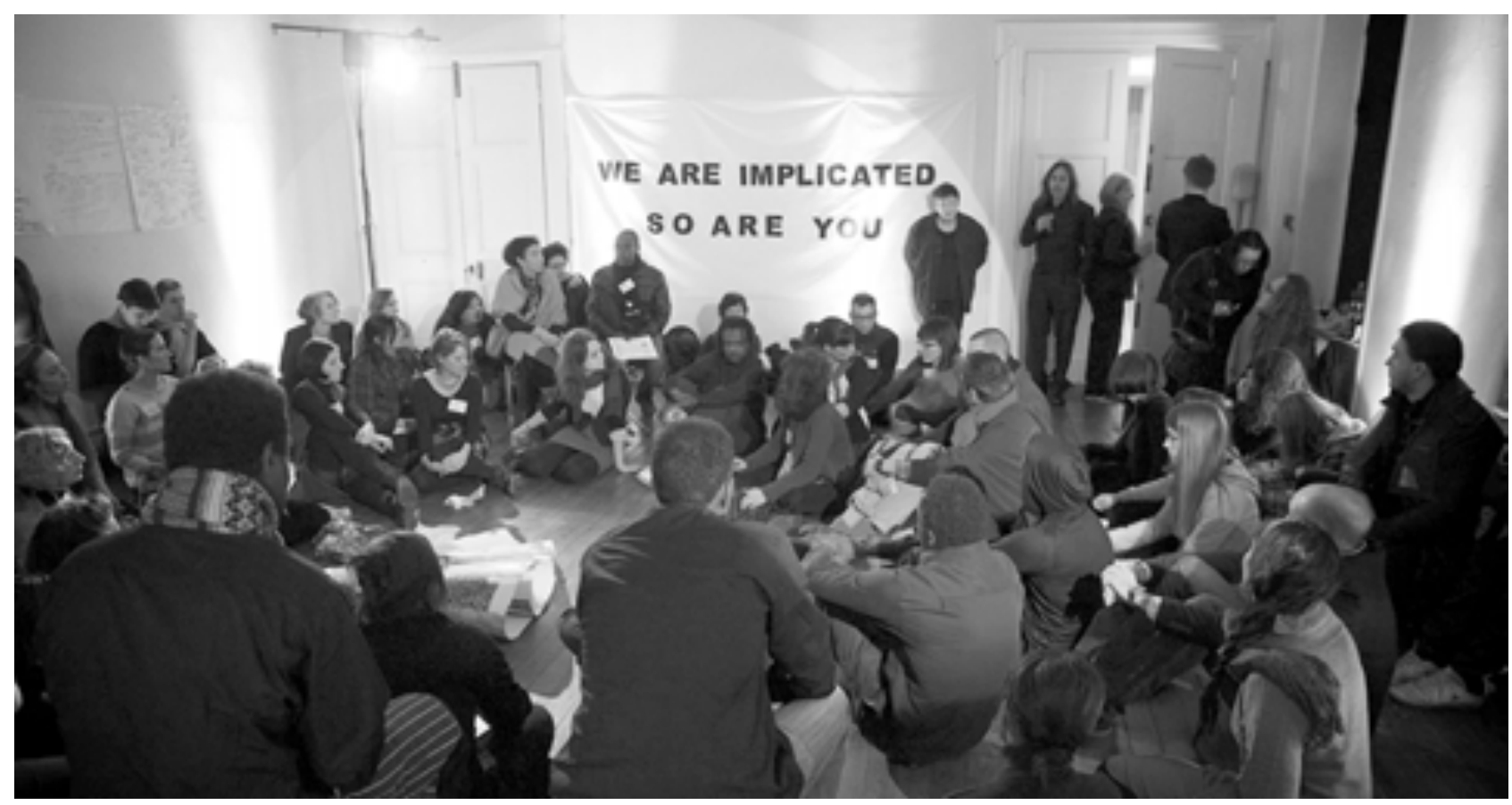

E-Book von Carmen Mörsch, carmen.moersch@zhdk.ch 27.01.2017 14:39 Copyright 2017, transcript Verlag, Bielefeld 